\title{
Ovarian follicular dynamics in Boran and Crossbred heifers in Ethiopia: Implications for assisted repro- ductive techniques
}

\author{
Jeilu Jemal ${ }^{*}$, Tamrat Degefa ${ }^{2}$, Tefera Yilma ${ }^{3}$, Sayid Ali², Alemayehu Lemma ${ }^{3}$ \\ ${ }^{1}$ National Agricultural Biotechnology Research Center, Animal Biotechnology Research \\ P O Box 249 Holeta, Ethiopia \\ ${ }^{2}$ Debre zeit Agricultural Research Center, Animal Biotechnology Research \\ ${ }^{3}$ Addis Ababa University, College of Veterinary Medicine and Agriculture, Department of Clinical \\ Studies \\ *Corresponding author: - Tel-+251911549606, E-mail: - juyee11@gmail.com
}

\begin{abstract}
The study was conducted to characterize the follicular dynamics of purebred Boran (Bos indicus) and Boran * Holstein Friesian crossbred heifers during estrous cycles; for use in ovum pick up and in-vitro embryo production. Insight of reproductive physiology of cattle would help to understand and exploit the reproductive potential of elite animals for breed improvement. Follicular development, growth and atresia during estrous cycles were evaluated using a trans-rectal real-time B-mode ultrasound system for three consecutive estrus cycles. Luteal activity was evaluated by serum progesterone level. Follicular aspirations were done to investigate the potential of Boran cattle and their crosses for transvaginal oocyte production; using a vacuum pressure pump and Aloka SSD Prosound-2 ultrasound device. Boran heifers $(\mathrm{n}=15)$ manifested two $(\mathrm{n}=6,40 \%)$, three $(\mathrm{n}=5,33 \%)$, four $(\mathrm{n}=3,20 \%)$ and five $(\mathrm{n}=1,6.7 \%)$ follicular waves. Crossbred heifers $(n=14)$ showed one $(n=2,14 \%)$, two $(n=6,43 \%)$ and three $(n=6,43 \%)$ follicular waves. Interovulatory interval was $21.1 \pm 3.4$ and $21.4 \pm 2.7$ days for Boran $(n=45)$ and crossbred $(n=42)$ heifers, respectively. The progesterone level in Boran and Crossbred heifers during diestrus was $9.5 \pm 11.0$ and $4.6 \pm 8.8 \mathrm{ng} / \mathrm{ml}$, respectively. The maximum diameter of the ovulatory follicle for crossbred heifers was higher $(15.4 \pm 1.6 \mathrm{~mm})$ than the diameter of the Boran $(14.0 \pm 1.9 \mathrm{~mm})$ heifers $(p<0.005)$. Differences $(p<0.005)$ were observed in the size of both right $(26.6 \pm 5.14$ and $28.6 \pm 5.1 \mathrm{~mm})$ and left $(21.7 \pm 4.85$ and $24.1 \pm 5.07 \mathrm{~mm})$ ovaries of Boran and Crossbred heifers, respectively. Difference $(p<0.005)$ was also observed in follicular count of the
\end{abstract}


right ovaries of Boran $(4.84 \pm 1.96)$ and Crossbred $(5.13 \pm 2.05)$ heifers. Oocyte recovery rate in once weekly collection scheme for Boran and their crossbred heifers was $(n=19,42.08 \%)$ and $(n=17,42.55 \%)$, respectively. The recovery rate for twice weekly collection scheme was $(n=24,34.53 \%)$ and $(n=23,40.44 \%)$ for Boran and crossbred heifers, respectively. Follicular dynamics in Boran heifers is characterized by a higher incidence of cycles with two, three and four waves, associated with a low persistence of the dominant follicles; and smaller size of ovulatory follicles and less intense heat signs from their crossbred counterpart. Boran heifers proved to have potential for comparable number of follicular population and ease of aspiration procedures that can be tapped for advanced reproductive techniques.

Keywords: Estrus cycle; follicular wave; ovarian follicle; ovum pickup; ultrasound.

\section{Introduction}

Increasing knowledge of ovarian physiology in cattle has provided opportunities for the improvements of assisted reproductive techniques over the years. The manipulation of ovarian function had great contribution to design protocols to control luteal and follicular function of ovaries in cattle. Cows can be classified as low, intermediate or high antral follicle count (AFC), according to the number of antral follicles detected via ovarian ultrasonography (Zangirolamo et al., 2018). A sound understanding of the processes involved in the growth and differentiation of antral follicles destined for ovulation is essential for artificial maturation of bovine oocytes and in developing improved hormonal regimens to control estrus in the cow (Gordon, 2003). Further, it is also important in improving techniques such as estrus synchronization, in vivo and in vitro embryo production and transfer. The maturation of bovine oocyte technique helps breeders to exploit the genetic potential of elite animals since young age. This would accelerate the genetic advancement rate of genetically superior animals (Baldassarre et al., 2018). Ovarian physiological characteristics can directly influence the number and quality of oocytes available for ovum pick up procedures (OPU) and in-vitro embryo production (IVEP) Lonergan et al (1994); which have great contribution on selection of elite females to be the parent of the next generation through assisted reproductive techniques.

Evaluation of antral follicles by ultrasound is considered the most practical strategy to recruit a female for reproductive improvement; and hence ultra- 
sound scanning is quite useful for studying follicular and luteal dynamics (Morotti et al., 2017). Follicles in cattle grow in wave-like pattern (Driancourt, 2001) and follicular population is related to the stage of the estrous cycle. Evans et al (1994) reported that follicular development in calves or heifers less than 36 weeks of age occurred in a wave-like pattern as early as 2 weeks. This has practical implications for OPU, IVEP and estrus synchronization work. OPU technique enables to aspirate follicles from immature oocytes and from animals that are not showing regular estrous cycles (Gordon, 2003).

Understanding the differences between breeds of cattle is also important for the establishment of correct reproductive management procedures (Viana et $a l ., 2000)$. Reproductive physiology of zebu cattle is not identical to the European breeds of cows, and differences are known to exist in characteristics such as diameter of dominant follicle (Figueiredo et al., 1997), ovulation moment and a higher number of follicular waves during the estrus cycle (Viana et al., 2000).

Ethiopian Boran cattle are a fast growing, fertile and good milk producer compared to other indigenous cattle breeds in Ethiopia (Haile et al., 2011). The growth, reproduction and milk production performance of Boran has been improved in different parts of the world including, South Africa, Kenya, Australia and USA (Haile et al., 2011). The breed has huge potential that could be tapped with appropriate reproductive tools in selection scheme breeding programs to improve its beef and dairy attributes. However, there is inadequate information regarding follicular population and transvaginal oocyte aspirations in zebu breeds in general. Hence, the mechanisms that controls follicular dynamics during estrous cycles in Boran and their crossbred cattle needs to be understood to optimize reproductive management techniques and make the best use of reproductive biotechnology tools. The aim of this study was to characterize ovarian follicular dynamics and determine oocyte production potential of Boran and its Holstein crosses for the purpose of recruiting these breeds for advanced assisted reproductive techniques.

\section{Materials and Methods}

\section{Location}

Experiments were conducted at Holeta Agricultural Research and National Agricultural Biotechnology Research Centers, Holeta, Ethiopia; from February to April and November to December 2019 and January 2020. Holeta is located 
about $29 \mathrm{~km}$ west of the capital city, Addis Ababa, with Longitudes $38^{\circ} 38^{\prime}$ east' Latitude $09^{\circ} 04^{\prime}$ north and with Altitude of 2,390 meters above sea level. The minimum and maximum temperatures at Holeta are $6.13^{\circ} \mathrm{C}$ and $22.8^{\circ} \mathrm{C}$, respectively. The rainfall pattern is bimodal with short rains from March to May and long rains from June to August. The mean annual rainfall is about 1,243.7 mm with peak rain in August.

\begin{abstract}
Animal
The study animals constituted indigenous purebred Boran $(\mathrm{n}=15)$ and Boran * Holstein Friesian (HF) Crossbred heifers $(n=14)$ that were used for follicular dynamics experiment. All the Crossbred heifers used for this experiment have $75 \%$ exotic blood level. The heifers were between 1.5 and 3 years of age. The mean $( \pm \mathrm{SD})$ body condition score (scale 1-5) of Boran and Crossbred heifers were $3.3 \pm 0.5$ and $3.4 \pm 0.5$, respectively. The mean $( \pm \mathrm{SD})$ body weight of Boran and Crossbred heifers were $266 \pm 27.7 \mathrm{~kg}$ and $297 \pm 25.4 \mathrm{~kg}$ during and few weeks before the start of the experiment, respectively.

All animals were allowed to graze on natural pasture. Hay made from grass (Pennisetum, Festuca, Eragrostis and Hyparrhenia) constituted the major proportion of the roughage supply. Concentrate composed of wheat by-products or maize (28-30\%); Noug seed cake (68-70\%; Guizotia abyssinica) and 1\% salt were used as supplementary feed for heifers every morning before the start of the experiment. Water was provided ad-libitum.
\end{abstract}

\title{
Procedure for characterizing follicular dynamics
}

Estrus was synchronized to bring experimental animals on similar reproductive stage, using an intramuscular injection of $2 \mathrm{ml} \mathrm{PGF}_{2 \mathrm{a}}$ (Estrumate, Germany) hormone. Date of ovulation (considered as day 0) was determined ultrasonically after animals showed behavioral estrus signs and thereafter, monitoring follicular dynamics was commenced. The nonidentity (mathematical) method was used to manage ultrasonic follicular data (Ginther, 1993). Estrus detection was scheduled twice a day and reported by assistants. Trans-rectal realtime B-mode ultrasound system with a $7.5 \mathrm{MHz}$ linear array rectal transducer (SIUI, CTS-3300V; Shantou, China) was used for serial scanning of the ovaries. Each animal was scanned at least for two consecutive cycles. Follicular diameter was measured by the internal electronic calipers and later grouped as small (3-5mm), medium $(6-8 \mathrm{~mm})$ and large $(\geq 9 \mathrm{~mm})$. Each time, the three 
largest follicles were measured and the total number of visible follicles counted in each ovary. At each scan, ovary size was measured (taking the dimension of the longest axis) in both right and left ovaries. Inter ovulatory interval (IOI) was defined as the length of time between successive ovulations. Date of wave Emergence was determined retrospectively from the date of ovulation (Day 0). Date of divergence (DD) was defined as the date at which the dominant follicle (DF) of the wave dramatically diverged in growth rate from the rest of its subordinate follicles (SF). Luteal activity was evaluated by serum progesterone concentrations. Blood samples were collected every other day using plain vacutainer tubes. The serum was separated and stored at $-20^{\circ} \mathrm{C}$ until analysis. Progesterone analyses were performed by serum progesterone analysis device (eProCheck ${ }^{\circledR} 2.0$ - 2400), using a commercial kit (Mini tube, Germany). Number of follicular waves, length of IOI, DD, growth and atresia rate, and total number of follicles in each ovary, follicular size and group, diameter of the largest follicle, diameter of ovulatory follicles and ovary size were used to compare the breeds.

\section{Procedure for follicular aspirations}

At the end of studying the follicular dynamics, follicles were aspirated from both breeds $(\mathrm{n}=12)$ on once and twice (three days interval) weekly collection scheme for three months. The OPU set-up had a real-time B-mode ultrasound system (Aloka SSD Pro Sound 2, Japan) with a 6.5-MHz convex sector probe transducer (Hitachi Medical Co., Tokyo, Japan) and a needle guide system (Mini tube, GmbH, Germany). Follicles were aspirated at $70-80 \mathrm{mmHg}$ vacuum pressure at a flow rate of $15-20 \mathrm{ml} / \mathrm{min}$. Oocytes were collected into a PBS media supplemented with heparin $20 \mu \mathrm{g} / \mathrm{ml}, 2 \% \mathrm{FCS}, 50 \mu \mathrm{g} / \mathrm{ml}$ gentamicin, and $25 \mathrm{mM}$ HEPS and maintained at $37^{\circ} \mathrm{C}$. Each heifer had received $2-3 \mathrm{ml}$ of epidural anesthesia (2\% lidocaine) before follicular aspiration procedures. Ethical clearance for animal research was granted by research ethical committee of AAU CVMA. Aspirated COCs were searched and categorized according to Seneda et al (2001) with some modifications as; Grade I= COCs with an even cytoplasm and three or more cumulus-cell-layers; Grade II= COCs with an even cytoplasm and less than three cumulus-cell-layers; Grade III= COCs at least with one layer of cumulus cells or partially denuded and Grade IV= Denuded oocytes. 


\section{Statistical analysis}

Data were grouped according to breed of animals and follicular characteristics in each estrous cycle. Descriptive statistics were used to determine the proportion of animals that exhibited different number of follicular waves. Frequency analysis and chi-square test were used to determine occurrence of ovulation. Differences between breeds on follicular population and among animals with the same number of follicular waves per cycle were evaluated by t-test, repeated measures and PROC-Mixed ANOVA. Differences in follicular growth and atresia characteristics among the breeds with similar follicular wave number were evaluated by $\mathrm{F}$ test. The relationship between the number of waves and estrous cycle length was estimated by Pearson's correlation method. Graphical analyses were performed using Microsoft offices excel. Results are shown as mean \pm standard deviation (SD) and level of significance was held at $P<0.05$.

\section{Results}

All except one heifer exhibited heat within 2-5 days after $2 \mathrm{ml} \mathrm{PGF}{ }_{2 a}$ hormone injection. Boran heifers $(n=15,100 \%)$ and crossbred heifers $(n=14,93.3 \%)$ exhibited behavioral heat in five consecutive days after 48 hours of PGF2 $\alpha$ injection. Prominent behavioral and physiological heat signs observed during heat manifestation period were mounting each other, vaginal discharge and bleeding.

The three estrous cycles evaluated for 69 days on purebred Boran and Boran * HF crossbred heifers manifested characteristic pattern of follicular waves, with the recruitment of a group of 3 to $5 \mathrm{~mm}$ follicles, followed by the selection, development and atresia of a dominant follicle. The Boran heifers $(n=15)$ manifested two (40\%), three (33\%), four (20\%) and five (6.7\%) follicular waves whereas the crossbred heifers $(\mathrm{n}=14)$ showed one $(14 \%)$, two $(43 \%)$ and three (43\%) follicular waves. 

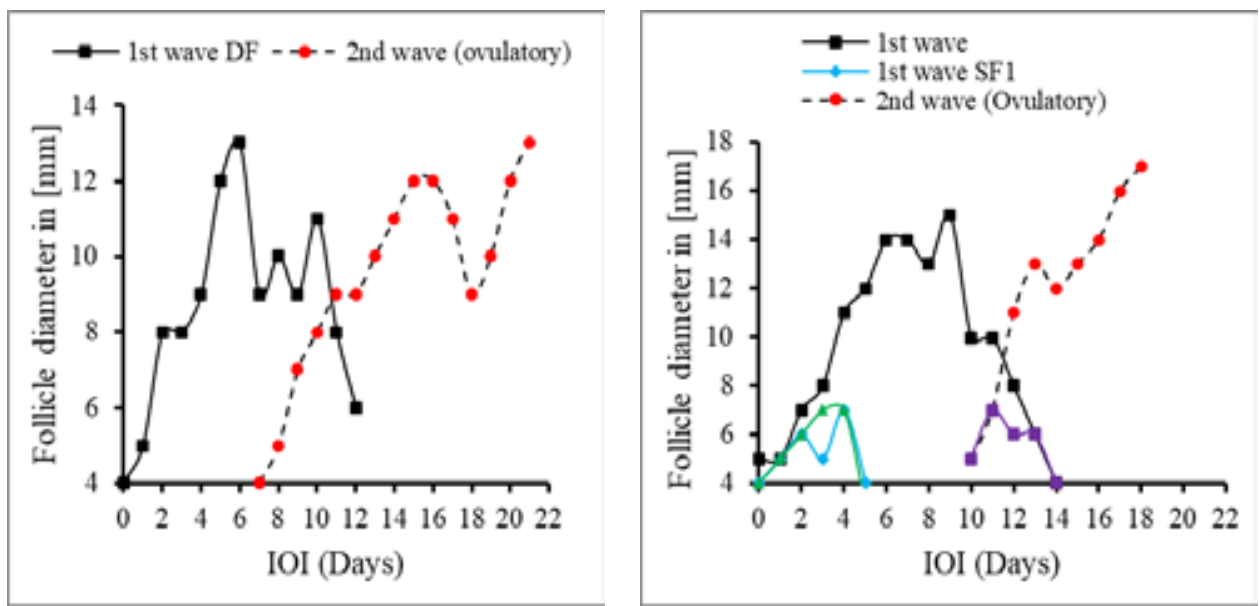

Figure 1. Two wave follicular development in Boran heifers (left panel) and crossbred heifers (right panel).

A Boran heifer (6.7\%) showed two follicular waves in the first and second estrus cycles and three follicular waves during the third cycle. A double ovulation was observed in two Boran heifers (13.3\%) and one crossbred heifer $(7.1 \%)$. Two Boran heifers (13.3\%) and one (7.1\%) crossbred heifer exhibited prolonged estrus signs (three days); and the size of ovulatory follicle remained constant or slightly reduced in size $(1 \mathrm{~mm})$ until they eventually ovulated and the behavioral estrus signs vanished. 

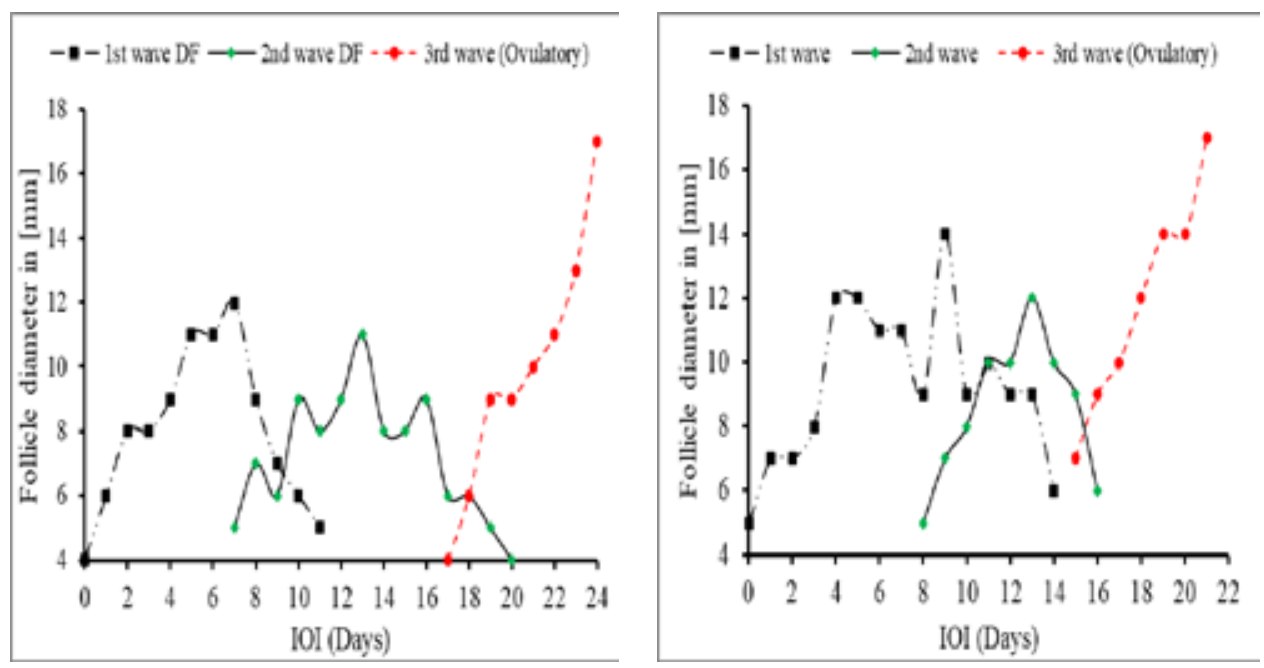

Figure 2. Three wave follicular development in a Boran heifer (left panel) and Cross bred heifer (right panel).

The majority of the Boran and crossbred heifers $(n=11,73 \%$ and $n=12,85 \%)$ respectively, exhibited estrus cycles with two and three follicular waves. The main characteristics of the follicular dynamics in these two breeds with two and three follicular waves are shown in Tables 1 and 2. There was no difference $(p>0.05)$ between Boran $(n=45)$ and crossbred $(n=42)$ heifers in IOI $(21.1 \pm$ 3.4 and $21.4 \pm 2.7$ days) and serum progesterone level $(9.5 \pm 11.0$ and $4.7 \pm 8.8$ $\mathrm{ng} / \mathrm{ml}$ ) during diestrus, respectively.

There was, however, a difference $(p<0.05)$ in IOI between the heifer with five follicular waves and other heifers with one, two, three and four follicular waves. There was a positive correlation $(p<0.05)$ between the number of follicular waves in a cycle and IOI $(r=0.27, p=0.05)$. There was a tendency of increase in the number of follicular waves with the prolongation of inter ovulatory interval. The mean IOI was $27.0 \pm 0.0$ days, for a heifer with five-wave cycles, $22.6 \pm 2.9$ days, for four-wave cycles, $20.8 \pm 2.9$ days for three-wave cycles and $19.5 \pm 3$ days for two-wave cycles, and $18.8 \pm 2.4$ days for one-wave cycle. 
The mean maximum diameter of the ovulatory follicle for crossbred heifers $(15.4 \pm 1.6 \mathrm{~mm})$ was higher than the diameter of the Boran heifers $(14 \pm 1.9$ $\mathrm{mm})(p<0.005)$.

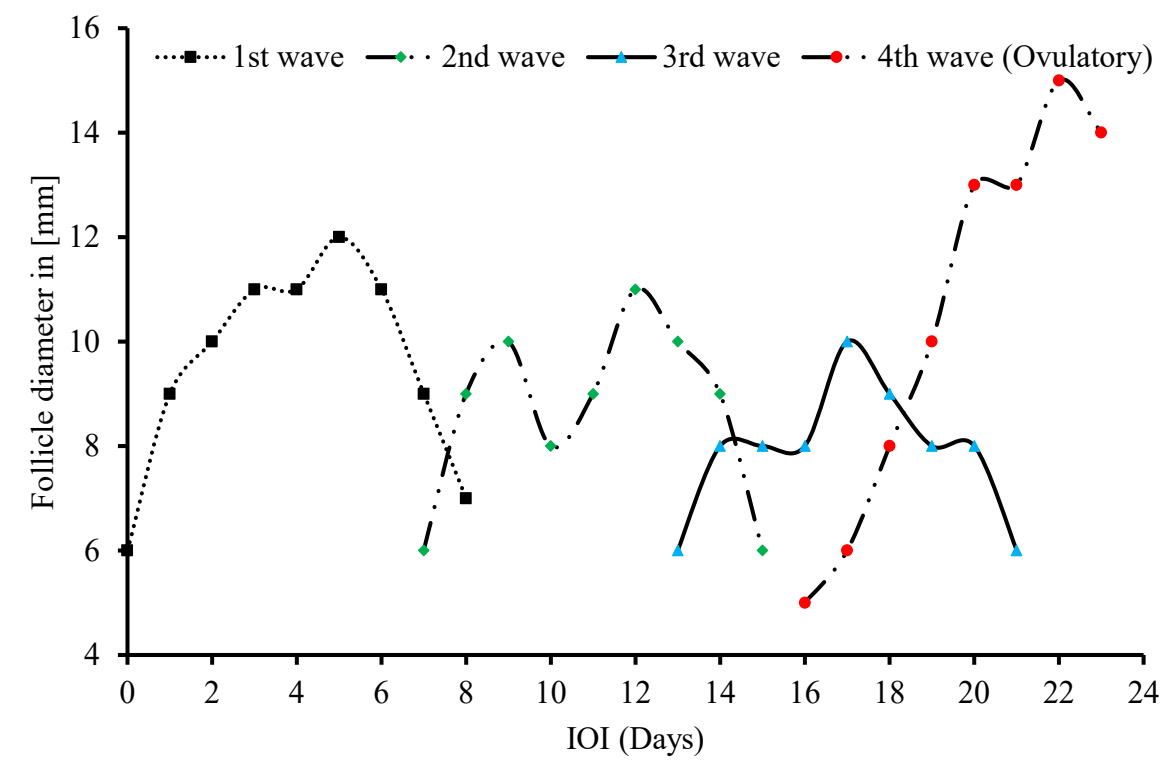

Figure 3. Four wave follicular development in a Boran heifer. The dynamics and size of the DF of the first, second, third and fourth (ovulatory) waves are indicated by solid lines with different symbols. 
Table 1. Characteristics of follicular waves, growth and atresia rate of dominant follicle in Boran and Crossbred heifers with two follicular waves during estrus cycle

\begin{tabular}{|c|c|c|}
\hline \multirow{2}{*}{$\begin{array}{l}\text { Characteristics } \\
(\text { mean } \pm \mathrm{SD})^{*}\end{array}$} & \multicolumn{2}{|c|}{ Follicular Waves } \\
\hline & First & Second \\
\hline \multicolumn{3}{|l|}{ Boran } \\
\hline Wave onset (day) & $0.59 \pm 0.71$ & $10.7 \pm 3.53$ \\
\hline Wave length (days) & $15.1 \pm 2.40$ & $10.0 \pm 2.26$ \\
\hline Day of maximum diameter (day) & $8.47 \pm 2.38$ & $19.5 \pm 2.98$ \\
\hline Maximum diameter (mm) & $12.1 \pm 1.56^{\mathrm{a}}$ & $14.2 \pm 1.63^{\mathrm{b}}$ \\
\hline Growth rate (mm/day) & $0.97 \pm 0.58^{\mathrm{a}}$ & $0.91 \pm 0.26^{\mathrm{a}}$ \\
\hline Divergence day (day) & $4.41 \pm 1.37$ & $13.8 \pm 3.50$ \\
\hline Length of growth phase (days) & $8.35 \pm 2.29$ & $8.82 \pm 4.02$ \\
\hline Atresia rate (mm/day) & $1.25 \pm 0.76$ & - \\
\hline \multicolumn{3}{|l|}{ Crossbred } \\
\hline Wave onset (day) & $0.83 \pm 0.62$ & $12.9 \pm 3.29$ \\
\hline Wave length (days) & $16.0 \pm 3.36$ & $10.9 \pm 2.19$ \\
\hline Day of maximum diameter & $9.50 \pm 2.60$ & $22.2 \pm 2.38$ \\
\hline Maximum diameter (mm) & $14.0 \pm 2.47^{\mathrm{a}}$ & $15.8 \pm 1.51^{b}$ \\
\hline Growth rate (mm/day) & $0.93 \pm 0.28^{\mathrm{a}}$ & $1.00 \pm 0.28^{\mathrm{a}}$ \\
\hline Divergence day & $3.67 \pm 1.41$ & $16.4 \pm 3.54$ \\
\hline Length of growth phase (days) & $9.50 \pm 2.60$ & $10.8 \pm 2.13$ \\
\hline Atresia rate (mm/day) & $1.41 \pm 0.69$ & - \\
\hline
\end{tabular}

The growth pattern for the first dominant follicle of Boran and crossbred heife rs with two waves emerged on day $(0.6 \pm 0.7$ and $0.8 \pm 0.6)$ and its regression occurred on day $(9.4 \pm 2.3$ and $10.5 \pm 2.6)$ of the estrus cycles, respectively. The dominant follicle reached its maximum diameter on day $8.5 \pm 2.4$ for pure Boran and $9.5 \pm 2.6$ for crossbred heifers. The second wave emerged on day 10.7 \pm 3.5 for Boran and 12.9 \pm 3.3 for crossbred heifers, the dominant (ovulatory) follicle selected on day $13.8 \pm 3.5$ for pure Boran, and $16.4 \pm 3.5$ for crossbred heifers. The maximum diameter of the dominant follicle for the first wave was smaller $(p<0.001)$ than the diameter of the second wave dominant (ovulatory) follicle in both breeds. 
Table 2. Characteristics of follicular waves, growth and atresia rate of dominant follicles in Boran and crossbred heifers with three follicular waves during the estrus cycle

\begin{tabular}{lccc}
\hline Characteristics & \multicolumn{2}{l}{ Follicular Waves } & \\
\hline (mean \pm SD)* & First & Second & Third \\
\hline Boran & & & \\
Wave onset (day) & $0.69 \pm 0.79$ & $7.06 \pm 2.18$ & $14.0 \pm 2.45$ \\
Wave length (days) & $11.4 \pm 2.68^{\mathrm{a}}$ & $11.8 \pm 2.62^{\mathrm{a}}$ & $8.25 \pm 1.57^{\mathrm{b}}$ \\
Day of maximum diameter & $6.63 \pm 1.20$ & $11.8 \pm 1.95$ & $20.8 \pm 2.91$ \\
Maximum diameter (mm) & $11.9 \pm 2.46^{\mathrm{a}}$ & $11.5 \pm 1.21^{\mathrm{a}}$ & $14.6 \pm 2.06^{\mathrm{b}}$ \\
Growth rate (mm/day) & $1.09 \pm 0.31^{\mathrm{a}}$ & $1.25 \pm 0.47^{\mathrm{a}}$ & $1.23 \pm 0.30^{\mathrm{a}}$ \\
Divergence day (DD) & $3.94 \pm 0.99$ & $10.2 \pm 1.97$ & $16.7 \pm 2.41$ \\
Length of growth phase (days) & $6.63 \pm 1.20$ & $6.06 \pm 3.02$ & $7.94 \pm 0.93$ \\
Atresia rate (mm/day) & $1.56 \pm 1.09$ & $1.29 \pm 0.61$ & \\
Crossbred & & & \\
Wave onset (day) & & & \\
Wave length (days) & $0.83 \pm 0.71$ & $8.22 \pm 2.92$ & $14.1 \pm 3.07$ \\
Day of maximum diameter & $6.17 \pm 2.53$ & $12.9 \pm 2.99$ & $21.50 \pm 2.71$ \\
Maximum diameter (mm) & $12.5 \pm 2.09^{\mathrm{a}}$ & $12.2 \pm 1.62^{\mathrm{a}}$ & $15.17 \pm 1.86^{\mathrm{b}}$ \\
Growth rate (mm/day) & $1.23 \pm 0.49^{\mathrm{a}}$ & $1.11 \pm 0.46^{\mathrm{a}}$ & $1.22 \pm 0.32^{\mathrm{a}}$ \\
Divergence day (DD) & $3.61 \pm 1.38$ & $10.7 \pm 3.29$ & $16.8 \pm 3.09$ \\
Atresia rate (mm/day) & & & \\
\hline * Mean followed & $1.36 \pm 0.56$ & $1.75 \pm 0.64$ & - \\
\hline
\end{tabular}

* Means followed by different letters within rows significantly differ at $p<0.05$.

The first wave in Boran and crossbred heifers with three follicular waves emerged on day $(0.7 \pm 0.8$ and $0.8 \pm 0.7)$ of the estrous cycle, respectively. The dominant follicle growth pattern of the first follicular wave for Boran and crossbred heifers with three follicular waves reached maximum diameter on day $6.6 \pm 1.2$ and $6.2 \pm 2.5$ and began atresia on day $7.6 \pm 1.2$ and $7.2 \pm 2.5$ respectively, showing a quite short period of stabilization or apex plateau.

The second wave showed up on day $7.1 \pm 2.2$ for Boran and $8.2 \pm 2.9$ for crossbred heifers, and the dominant follicle had selected on day $(10.2 \pm 1.97$ and $10.7 \pm 3.3)$ reaching maximum diameter on day (11.8 \pm 2.0 and $12.9 \pm 3.0)$ and beginning atresia on day $(13.7 \pm 2.2$ and $14.7 \pm 3.1)$ respectively, for pure Boran and Boran * HF cross heifers. 
The third wave (ovulatory) emerged on day (14.0 \pm 2.5 and $14.1 \pm 3.1)$, with the dominant follicle being selected on day (16.7 \pm 2.4 and $16.8 \pm 3.1)$ and reaching its maximum diameter on day $(20.8 \pm 2.9$ and $21.5 \pm 2.7)$ of the estrus cycle, respectively.

The ovulatory follicle developed in the right ovary in proportion of $(62 \%, \mathrm{n}=45)$ in Boran heifers and $(60 \%, \mathrm{n}=42)$ in crossbred heifers.

Table 3. Comparison of the size of ovaries in Boran and Crossbred heifers

\begin{tabular}{llcccc}
\hline Ovary size & Breed & N & $\begin{array}{l}\text { Mean } \pm \text { SD } \\
\text { Size of ovary [mm] }\end{array}$ & t & P \\
\hline Right ovary & Boran & 820 & $26.6 \pm 5.14^{\mathrm{a}}$ & -7.92 & 0.000 \\
& Cross & 815 & $28.6 \pm 5.10^{\mathrm{b}}$ & & \\
\multirow{2}{*}{ Left ovary } & Boran & 817 & $21.7 \pm 4.85^{\mathrm{a}}$ & -9.84 & 0.000 \\
& Cross & 808 & $24.1 \pm 5.07^{\mathrm{b}}$ & & \\
\hline
\end{tabular}

There was difference $(p<0.001)$ between the size (both right and left) of purebred Boran and crossbred heifers ovaries and follicular count of the right ovaries. However, there was no difference $(p>0.05)$ in the total follicular count of the left ovaries. The mean number of follicular populations per animal was $9.4 \pm 3.0$ for Boran heifers and $9.6 \pm 3.3$ for crossbred heifers. Regarding the size, the mean number of small, medium and large follicles was (5.6 $\pm 3.0,2.5$ \pm 1.3 , and $1.3 \pm 0.9$ ) respectively for Boran heifers and the mean number of small, medium and large follicles for Crossbred heifers was $(5.5 \pm 3.3,2.4 \pm 1.3$ and $1.7 \pm 1.0)$ respectively. A repeated measures ANOVA, with GreenhouseGeisser correction was conducted to assess differences between the means of the three groups of follicles. Results indicated that there was difference $F$ (1.5, $45005)=3514, p<0.001$ between the populations of the three follicular groups in both breeds. Examination of these means indicated that small and medium follicles combined were found more abundantly $(84 \%, \mathrm{n}=1732)$ in both breeds than the large follicles and with the mean number of $(8.16 \pm 3.13, \mathrm{n}=871$ and $7.89 \pm 3.50, \mathrm{n}=859)$ for Boran and Crossbred heifers, respectively, during the three estrus cycles.

A mixed ANOVA was conducted to assess the follicular population difference between Boran and Crossbred heifers. Results indicated there was no difference between the breeds in the mean count of the follicular groups, $F(1,1724)$ $=0.005, p=0.94$. 
The mean number of right ovaries follicular count for Crossbred heifers is higher $(p<0.003)$ than Boran heifers. However, there is no difference in total number of follicular populations between the breeds.

Table 4. Comparison of follicular counts in the right and left ovaries of Boran and crossbred heifers

\begin{tabular}{lllccc}
\hline Follicular counts & Breed & N & $\begin{array}{l}\text { Mean ( } \pm \text { SD) } \\
\text { No of follicles }\end{array}$ & $t$ & $p$ \\
\hline Right ovary & Boran & 870 & $4.84 \pm 1.96^{\mathrm{a}}$ & -2.97 & 0.003 \\
& Cross & 856 & $5.13 \pm 2.05^{\mathrm{b}}$ & & \\
Left ovary & Boran & 871 & $4.56 \pm 1.96^{\mathrm{a}}$ & 0.34 & 0.735 \\
& Cross & 855 & $4.53 \pm 1.95^{\mathrm{a}}$ & & \\
\hline
\end{tabular}

Oocyte recovery rate for the once weekly and twice weekly collections scheme was $42.3 \%(n=36)$ and $37.4 \%(n=47)$, respectively. Oocyte recovery rate for Boran and Crossbred heifers in once weekly collection scheme was $42.1 \%(\mathrm{n}=19)$ and $42.6 \%(\mathrm{n}=17)$, respectively. The recovery rate in twice weekly collection scheme was $34.5 \%(n=24)$ and $40.4 \%(n=23)$ for Boran and Crossbred heifers, respectively. The mean number of oocyte collected in a once weekly scheme was (5.6 \pm 2.2 and $5.9 \pm 2.1)$ for purebred Boran and crossbred heifers, respectively. The mean number of aspirated oocyte in twice weekly collection scheme was $(2.8 \pm 1.7$ and $3.1 \pm 2.3)$ for Boran and their crosses, respectively. There was no difference $(p>0.05)$ between purebred Boran and crossbred heifers in total number of oocyte aspirated in the once and twice weekly OPU session.

Table 5. Number of COC obtained in Boran and Crossbred heifers by once and twice weekly follicular aspirations scheme

\begin{tabular}{lccccccc}
\hline $\begin{array}{l}\text { Follicular } \\
\text { Aspiration }\end{array}$ & Breed & N & $\begin{array}{l}\text { Mean ( } \pm \text { SD)* } \\
\text { No of COC }\end{array}$ & GI & GII & GIII & GIV \\
\cline { 2 - 8 } & Boran & 19 & $5.58 \pm 2.16^{\mathrm{a}}$ & 1.00 & 1.58 & 1.79 & 1.21 \\
\hline Once weekly & Cross & 17 & $5.88 \pm 2.05^{\mathrm{a}}$ & 1.18 & 1.41 & 1.88 & 1.41 \\
& Bwice weekly & 24 & $2.79 \pm 1.69^{\mathrm{a}}$ & 0.58 & 1.13 & 0.67 & 0.42 \\
& Cron & 23 & $3.13 \pm 2.30^{\mathrm{a}}$ & 0.78 & 1.13 & 0.91 & 0.30 \\
\hline${ }^{*}$ Means followed by different letters within column differ $(p<0.005)$. & & & &
\end{tabular}

There was difference $(p<0.001)$ in mean number of oocyte collected per session between once $(5.72 \pm 2.09)$ and twice $(2.96 \pm 2.0)$ a week collection scheme. 
There was no difference between the breeds regarding the number of quality oocyte collected by both (once and twice weekly) collections.

\section{Discussion}

All animals except one heifer exhibited heat within five consecutive days after estrus synchronization. Behavioral signs of heat were weaker in Boran heifers as compared to crossbred heifers. During pro-estrus, estrus and met-estrus the Crossbred heifers manifested a good deal of behavioral estrus signs (mounting each other, vaginal discharge and bleeding) and have higher interaction among them. Estrus signs in Boran heifers were mostly observed during rectal palpation (vaginal discharge) and when the animals mixed with Crossbred heifers (mounting). Bleeding at the end of estrus period never manifested in Boran heifers. The practical implication of this phenomenon during estrus synchronization work should be emphasized. Local zebu breeds require intensive follow up for proper heat detection and timely insemination.

The three estrous cycles evaluated for 69 days on both breed of heifers manifested characteristic pattern of follicular waves. Two- and three- wave cycles occurred in the majority of animals $(\mathrm{n}=23,79.3 \%)$ during the estrus cycles. The incidence of higher estrus cycles with two and three follicular waves was also observed in European Taurus breeds (Savio et al., 1988) and Zebu cows (Gambini et al., 1998). Zebu breeds tend to have more follicular waves compared to B. Taurus breeds (Viana et al., 2000). The length of the luteal phase is considered as the main factor determining the number of follicular waves (Figueiredo et al., 1997). The length of inter ovulatory interval had shown no difference between the breeds. This result is in agreement with previous work (Degefa et al., 2016) in Ethiopian Boran and their crossbred cows' estrous cycle length. Long luteal phase maintains a high serum progesterone concentration that suppresses ovulation of the dominant follicle hence, inducing their atresia and onset of a new follicular wave (Gong et al., 1995).

The marked decline in diameter of the second dominant (ovulatory) follicle (indicated in the right panel of figure: 1) of Boran heifer with two follicular waves could be due to abrupt energy imbalance. Nutrition has effect on animal reproduction and follicular development. A report by Rhodes et al (1995) on Bos-indics cows that had negative energy balance indicated a reduction in dominant follicle maximum diameter, growth rate and persistence of dominant follicle. Follicular dynamics, behavioral heat manifestation and oocyte quality can be 
impacted by dietary energy and protein intake that related with the function of the ovarian insulin-like growth factor system. Crossbred heifers had higher diameter of ovulatory follicle than Boran heifers. Muraya, (2013) reported that the maximum diameter of ovulatory follicle in Kenyan Boran cows' was smaller than those reported in European cows by Ginther et al (1989). But comparable in size with other Bos indicus cows (Figueiredo et al., 1997). There was no difference in dominant or subordinate follicles growth or atresia rates between the breeds and between animals with different follicular waves. Follicular dynamics in Boran heifers is characterized by a higher incidence of cycles with two, three and four waves, associated with a low persistence of the dominant follicle, however, in this current observation in few animals $(n=2,13.3 \%)$ the dominant follicle remained for longer times (three days) without ovulation. The failure of the dominant follicles to ovulate could be due to lack of $\mathrm{LH}$ serge. LH pulse frequency is the key determinant of the fate of the dominant follicle (Duffy et al., 2000).

Occurrence of double ovulation was manifested in Boran heifers. This phenomenon could either be a defect in the deviation mechanism or a case in which twining would normally occur (Fricke and Wiltbank, 1999). Wiltbank et al (2000) reported the occurrence of more than one dominant follicle during a follicular wave in monovular species. The dominant follicles in both breeds developed in the right ovaries in higher proportion than the left ovaries. This incidence is attributed to high frequency of corpora lutea present in the right ovaries (Viana et al., 2000) and to the fact that these ovaries receive more blood supply compared to the left ones (Muraya, 2013).

There was no difference in total number of follicular populations between the breeds. However, there was difference in mean number of follicular counts of the right ovaries between the breeds. Boran heifers have a fairly comparable follicular population with Boran*HF crosses. In recent study, Degefa et al (2016) reported the total number of follicles greater than $4 \mathrm{~mm}$ in diameter for Ethiopian Boran cows is similar to the number reported for Bos taurus breeds (Bastos et al., 2010) and lower than the number of follicles reported for Nelore. The greater number of growing ovarian follicles in Ethiopian Boran cattle would help for OPU and subsequent IVEP (Degefa et al., 2016). As it was the case in this study and previous reports, different cattle breeds present different follicle numbers on the ovaries in a follicular wave cycle. The number of antral follicles is highly repeatable in the same animal over several evaluations even though there is considerable variability among individual cows 
(Morotti et al., 2017) and improved reproductive parameters and response to reproductive technologies in cows with higher antral follicle also count (SilvaSantos et al., 2014).

The mean number of oocyte retrieved in once weekly collection scheme from Boran heifers was comparable with Crossbred heifers. There was no difference in mean number of oocyte retrieved in twice weekly collection scheme (which is done in three days interval) between Boran and crossbred heifers. There was difference $(p<0.001)$ in mean number of oocyte collected per session between once and twice a week collection scheme. The recovery rate in both breeds was less than $50 \%$. This could be due to technician skill on aspiration and searching, vacuum pressure and also animal handling facility. Boran heifers had ease of anatomical structure for OPU work compared to their crossbred counterpart. The size of the probe holder that meant for European breed (mini-tube, Germany) had no negative effect on the ease of oocyte collection process in Boran heifers. Once weekly follicular aspiration scheme was more convenient than twice weekly collection scheme for coordination of field and lab works and for longer time repeated collections.

Introduction of advanced reproductive biotechnology techniques such as IVEP in Ethiopian cattle production systems believed to hasten the process of breed improvement activities. It offers an opportunity for cattle breeding and improvement centers to deliver embryo as a genetic improvement and multiplication tool beside semen. To our knowledge, this is the first study in Ethiopia that focused on the investigation of the potential of zebu breed for oocyte retrieval. Boran breed proved to be capable of producing oocyte in comparable quantity and quality with Boran*HF crosses. IVEP like other assisted reproductive techniques could help to enhance genetic gain from these cattle by shortening the generation interval and by increasing accuracy of selection. Knowledge of follicular dynamics help in tackling some underling infertility problems such as delayed ovulation and silent heat manifestation (which is prominent in local cattle breeds), and may increase efficiency of AI by predicting exact ovulation time for proper insemination. The breeding program should give focus for these techniques to exploit the genetic potential of local zebu breed for milk and meat production. 


\section{Conclusion}

There are marked differences in the follicular dynamics between purebred Boran heifers and their Holstein Frisian crosses. In the Boran, it is characterized by a higher number of follicular waves, smaller size of ovulatory follicles and less intense heat signs. Behavioral signs of heat were weaker in Boran heifers as compared to crossbred heifers. Boran heifers proved to have potential for comparable number of follicular population and ease of aspiration procedures that can be tapped for advanced reproductive techniques. For longer time repeated collections and coordination of field and lab work, once weekly follicular aspiration had advantage over twice weekly aspirations.

Further improvement of the procedures such as, optimizing vacuum pressure, needle operation and aspiration time, hygienic oocyte collection environment, COCs transportation equipment and proper temperature maintenance for laboratory equipment would go long ways in enhancing local and national capacity to run a full-fledged bovine IVF laboratory. Boran cattle could be a good candidate for implementation of OPU-IVP embryo production program in Ethiopia.

\section{Acknowledgements}

The authors gratefully acknowledged the financial and research inputs support of this study by the Ethiopian Institute of Agricultural Research (EIAR), National Biotechnology Research Center (NABRC). The financial support of Agricultural Growth Project (AGP II) of the (EIAR).The provision of experimental animals by Holeta Agricultural Research Center (HARC). And, the assistance of Tariku Bekele, Teshome Asfaw and Teshome Nigusse is gratefully acknowledged.

\section{References}

Baldassarre, H., Currin, L., Michalovic, L., Bellefleur, A., Gutierrez, K., Mondadori, R. G., et al., 2018. The interval of gonadotropin administration for in vitro embryo production from oocytes collected from Holstein calves between 2 and 6 months of age by repeated laparoscopy. Theriogenology, 116: 64-70.

Bastos, M.R., Mattos, M.C.C., Meschiatti, M.A.P., Surjus, R.S., Guardieiro, M.M., Mourão, G. B., et al., 2010. Ovarian function and circulating hormones in nonlactating Nelore versus Holstein cows. Acta. Sci. Vet., 38: 776.

Ethiop. Vet. J., 2020, 24 (2), 54-72 
Degefa, T., Lemma, A., Jemal, J., Mamo, G., Tegegne, A. and Youngs, C.R., 2016. Ovarian follicular dynamics in purebred and crossbred Boran cows in Ethiopia. Afr. J. Biotechnology., 15(33): 1763-1770.

Driancourt, M.A., 2001. Regulation of ovarian follicular dynamics in farm animals: Implications for manipulation of reproduction. Theriogenology, 55: 1211-1239.

Duffy, P., Crowe, M.A., Boland, M.P. and Roche, J.F. (2000): Effect of exogenous LH pulses on the fate of the first dominant follicle in postpartum beef cows nursing calves. J. Reprod. Fertil., 118: 9-17.

Evans, A.C., Adams, G.P. and Rawlings, N.C., 1994. Follicular and hormonal development in pre-pubertal heifers from 2 to 36 weeks of age. J. Reprod. Fertil., 102: 463-470.

Figueiredo, R.A., Barros, L. M., Pinheiro, O.L. and Soler, J.K.P., 1997. Ovarian follicular dynamics in Nellore breed (Bos indicus) cattle. Theriogenology, 47: 1489-1505.

Fricke, P.M., Wiltbank, M.C., 1999. Effect of milk production on the incidence of double ovulation in dairy cows. Theriogenology, 52: 1133-1143.

Gambini, A.L.G, Moreira, M.B.P., Castilho, C. and Barros, C.M., 1998. Follicular development and synchronization of ovulation in Gir cows. Rev. Bras. Reprod. Anim., 222: 1-210.

Ginther, O.J., Knopf, L. and Kastelic, J.P., 1989. Temporal association among ovarian events in cattle during estrous cycles with two and three follicular waves. J. Reprod. Fertil., 87: 223-230.

Ginther, O.J., 1993. A method for characterizing ultrasonically-derived follicular data in heifers. Theriogenology, 39: 363-37.

Gong, J.G., Wilmut, I., Bramley, T.A. and Webb, R.,1995. Pretreatment with recombinant bovine somatotrophin enhances the super ovulatory response to FSH in heifers. Theriogenology, 43: 221.

Gordon, I., 2003. Laboratory production of cattle embryos. CAB international publishing, 2nd edition, Biotechnology in agriculture series, No. 27.

Haile, A., Ayalew, W., Kebede, N., Dessie, T. and Tegegn, A. 2011. Breeding strategy to improve Ethiopian Boran cattle for meat and milk production. IPMS (Improving Productivity and Market Success) of Ethiopian Farmers Project Working Paper 26. Nairobi, Kenya, ILRI.

Lonergan, P., Monaghan, P., Rizos, D., Boland, M.P. and Gordon, I., 1994. Effect of follicle size on bovine oocyte quality and development competence following maturation, fertilization and culture in vitro. Mol. Reprod. Dev., 37: 48-53. 
Morotti, F., Santos, G.M.G., Koetz, J.C., Silva-Santos, K.C., Roso, V.M. and Seneda, M.M., 2017. Correlation between phenotype, genotype and antral follicle population in beef heifers. Theriogenology, 91: 21-26.

Muraya, J., 2013. A study of follicular dynamics in the Kenyan Boran cow. MSc Thesis. University of Nairobi. https://www.pdfs.semanticscholar.org

Rhodes, F.M., De'ath, G. and Entwistle, K.W., 1995. Animal and temporal effects on ovarian folicular dynamics in Brahman heifers. Anim. Reprod. Sci., 38: 265-277.

Savio, J.D., Keenan, L., Boland, M.P. and Roche, J.F., 1988. Pattern of growth of dominant follicles during the oestrous cycle of heifers. J. Reprod. Fertil., 83: 663-671.

Seneda, M.M., Esper, C.R., Garcia, J.M, Oliveira, J.A, Vantini, R., 2001. Relationship between follicle size and ultrasound guided transvaginal recovery. Anim. Reprod. Sci., 67: 37-43.

Silva-Santos, K.C., Santos, G.M.G., Koetz, J.C., Morotti, F., Siloto, L.S., Marcantonio, T.N., et al., 2014. Antral follicle populations and embryo production - in vitro and in vivo of Bos indicus-taurus donors from weaning to yearling ages. Reprod. Dom. Anim., 49: 228-232.

Viana, J.H.M., Ferreira, A.D.M., Ferreira, W. and Camargo, L.S., 2000. Follicular dynamics in Zebu Cattle. Pesq. Agropec. Bras., 35: 2501-2509.

Wiltbank, M.C., Fricke, P.M., Sangritasvong, S., Sartori, R. and Ginther, O. J., 2000. Mechanisms that prevent and produce double ovulations in dairy cattle. J. Dairy Sci., 83: 2998-3007.

Zangirolamo, A.F., Morotti, F., Nathalia, S., Tamires, K.S. and Marcelo, M.S., 2018. Antral follicle populations and embryo production. Anim. Reprod., 15: 310-315. 